\title{
A rare case of accidental swallowing and uneventful expulsion of a dental mouth mirror
}

\author{
Selvendran K E ${ }^{*}$, Madhuram K ${ }^{1}$, Naveenkumar $V^{1}$, Ashok Leburu ${ }^{1}$, Praveen $\mathrm{N}^{1}$ and Dhanavel $\mathrm{C}^{2}$ \\ ${ }^{1}$ Department of Conservative Dentistry and Endodontics, Karpaga Vinayaga Institute of Dental Sciences, Affiliated to the Tamilnadu Dr. MGR Medical University, \\ Chennai, Tamilnadu, India \\ ${ }^{2}$ Department of Conservative Dentistry and Endodontics, Indira Gandhi Institute of Dental sciences, Affiliated to Sri Balaji Vidyapeeth University, Pondicherry, India
}

\begin{abstract}
Accidents are unpleasant incidences that happen when we are careless or when we do not follow the safety rules. In the dental office, foreign body ingestion or aspiration is a rare but serious mishappening. Ingestion of blunt foreign objects is less life-threatening and the object is generally egested through the gastrointestinal tract uneventfully, but instrument may sometimes cause intestinal perforation. Aspiration, on the other hand, is a more serious, but fortunately, less prevalent hazard and often leads to hospitalization of the patient. From a legal aspect also, such incidence is counted as negligence on the part of the operator and the dentist should be well aware of the legal liabilities and should take the appropriate preventive measures to prevent or intercept any untoward circumstance.
\end{abstract}

\section{Introduction}

An accident is an incidental and unplanned event or circumstance, often with lack of intention or necessity. In dentistry foreign bodies vary in size and shape and range from endodontic instruments, dental clamps, lip clip, burs, posts, teeth, orthodontic bands and brackets, implant components, restorations and even tooth brush [1-9].

Grossman determined that $87 \%$ of the ingested foreign bodies entered the gastrointestinal tract and $13 \%$ entered the respiratory tract [10].

Most of the foreign bodies that entered the gastrointestinal tract pass spontaneously, only $10-20 \%$ cases require non-surgical intervention and $1 \%$ or less requires surgical removal [11]. However, swallowing the head of a dental mouth mirror is a rare occurrence during dental examination. In literature, only one such case has been reported till date [12]. The present paper discusses accidental ingestion of the head of a stainless steel mouth mirror by a young male patient, which over a period of time passed uneventfully through his digestive tract after 6 hours.

\section{Case report}

A 14 year old systemically healthy male patient reported to Department of Conservative dentistry and Endodontics, Karpaga vinayaga institute of Dental sciences, with a chief complaint of caries in his left lower back tooth region.

On dental examination, mandibular left first molar was found carious. On radiographic evaluation caries in mandibular first molar was seen without involvement of pulp. So routine restorative treatment was planned.

During the cavity preparation, patient was in supine position and mouth mirror was used for retracting the cheek. Unknowingly the head of the mouth mirror got detached from the mouth mirror handle and slipped into the patient's throat due to excessive salivation during examination. The patient did not have any gag reflex. The clinician noticed the missing mouth mirror head. When the patient was questioned about the missing mouth mirror head he replied that there was a mild pain in his throat. Patient was immediately seated in upright position and instructed to cough vigorously. But the mouth mirror head could not be retrieved. Patient was forcefully patted at the back region but that maneuver was also unsuccessful.

A thorough examination performed using a tongue depressor was also not productive. There was no evidence of airway compromise, respiratory distress or abdominal tenderness. Patient was informed about the accident and was assured.

Patient was immediately considered as an emergency case and sent to the department of emergency intervention. On medical examination the patient's vital signs were normal and there was no vomiting or difficulty in swallowing.

A postero anterior radiograph in the chest region was taken. Initial radiograph showed a radio opaque mouth mirror head in the duodenum (Figure 1). The patient was given high roughage diet and bananas to ease the passage of an object in his digestive tract. After 1 hour another PA chest radiograph was taken. The mouth mirror head had moved to the small intestine (Figure 2). The patient was continued with high fiber diet and bananas.

Another radiograph was taken after one and half hour. The mouth mirror head had crossed the narrowest ileo- caecal sphincter and

${ }^{\star}$ Correspondence to: Selvendran K E, MDS, Department of conservative dentistry and endodontics, Karpaga Vinayaga Institute of Dental Sciences, Affliated to the Tamilnadu Dr. MGR medical university, Chennai, Tamilnadu, India, E-mail: selvendranmds@gmail.com

Received: January 29, 2019; Accepted: February 05, 2019; Published: February 08, 2019 
had reached the large intestine (Figure 3). The patient was continued with the same diet. After 3 hours, during defaecation, mouth mirror head was passed through his stools and confirmed with a radiopgraph (Figure 4)

Patient was kept under observation for $24 \mathrm{hrs}$ and then discharged.

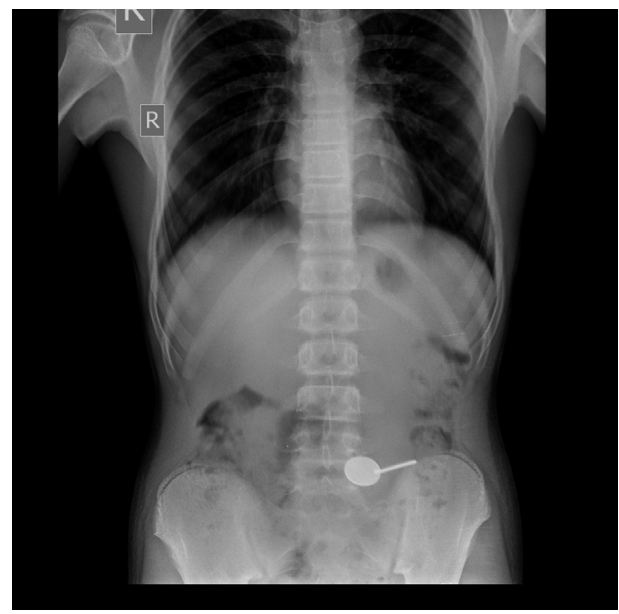

Figure 1. Mouth mirror in DUODENUM

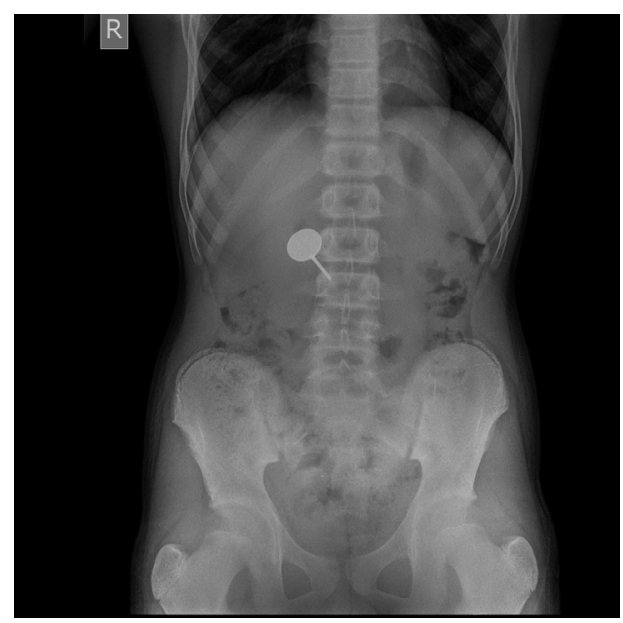

Figure 2. Mouth mirror in ILEUM

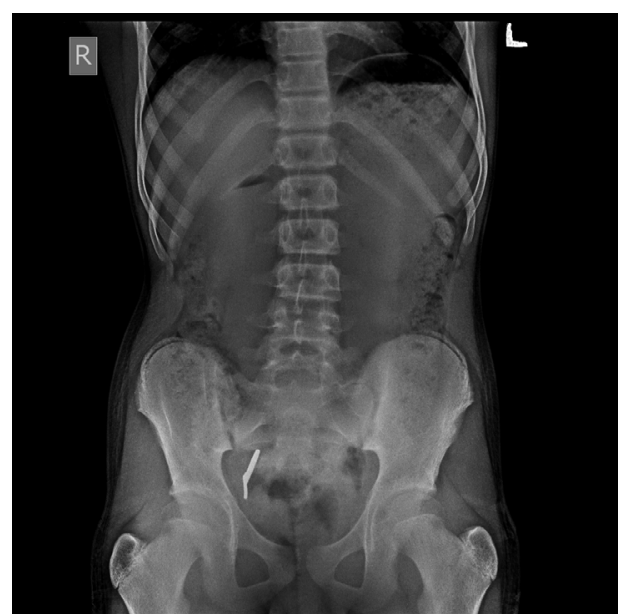

Figure 3. Mouth mirror in ILEO CAECAL JUNCTION

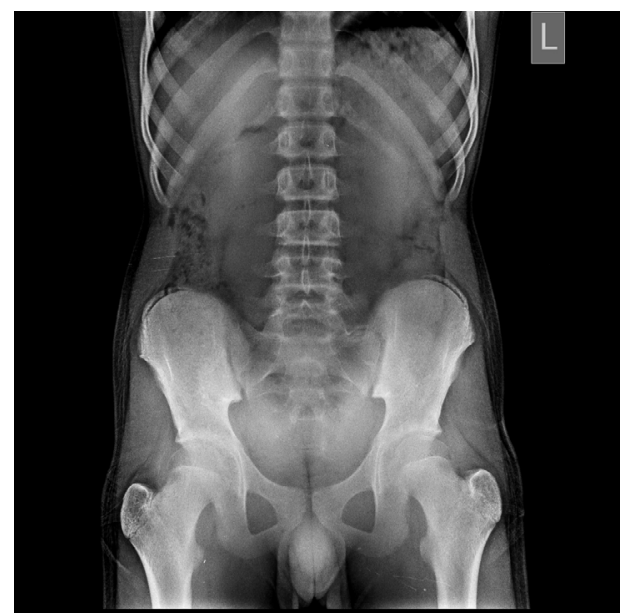

Figure 4. No trace of instrument (after expulsion)

\section{Discussion}

This case reports an unusual aspiration of a mouth mirror head and its uneventful retrieval. It has been reported that patients who often swallow foreign bodies form select groups: Prisoners, psychotic individuals, people with alcoholism, mentally retarded individuals, patients who are nervous or restless and patients with an excessive gag reflex $[13,14]$. When swallowed foreign bodies are not diagnosed and treated appropriately, they may cause serious complications. Although $80-90 \%$ of swallowed small foreign objects pass through the body without incident over the course of days to weeks $[15,16]$.

Ingestion/aspiration are potentially dangerous and carry the risk of causing life threatening or serious complications aschoking, oesphageal tissue perforation, intestinal ulceration/puncture, bronchial stenosis, abscess formation, hemorrhage or fistula [17].

Rapid localization is extremely helpful in the removal of swallowed/ aspirated foreign bodies [18].

Chest and /or abdominal radiographs are diagnostic for swallowed or aspirated radio opaque items. Some objects are made of materials that lack radio opacity, which makes it impossible to identify their position. Diagnostic bronchoscopy or computed tomography for localization is then required $[19,20]$.

If swallowing liquid is easy for the patient, then soft foods like bread or banana can be given. If swallowing soft diet is easy for the patient, then fruits can be added to the diet which would help move the swallowed object down the digestive tract. In this case banana with liquids were given to the patient.

Inflammatory bowel disease, tumors, diverticula, hernias, adhesions, anatomic narrowing or acute angulations of the alimentary canals also increase the risks of perforation [21]. Fortunately, the patient had good general health with no history of bowel disease.

Physical barrier methods alone do not completely prevent aspiration or ingestion as what happened in the present case because such an unusual event may happen in any phase of dental treatment.

Appropriate control of dental instruments is another method of preventing aspiration or ingestion. This applies particularly to instruments composed of few pieces such as dental mirrors, where soldered coupling areas that connect the handle and the head of the mirror are potentially weak sites because of frequent use and/or 
sterilization procedures. Mouth mirrors also have a detachable cork and screw joint connecting the shaft and the head of the mirror, which can get loosened during use and /or sterilization. Periodic inspection of these detachable joints also would have prevented an accident as happened in the present case.

Other common strategies to prevent aspiration / ingestion of foreign bodies

1. Use of a rubber dam

2. Use of a gauze throat pack

3. Use of a high velocity evacuation

4. Using more upright position of patient if possible

5. Use of wash field technique

6. Providing thorough instructions to the patient [22].

\section{Conclusion}

Proper handling of dental instruments requires particular care, especially where the patient is in supine or semi recumbent position because prevention is always better than cure. But in case of an unfortunate situation of an accidental swallowing of a dental instrument, the dentist should be able to manage it efficiently following proper guidelines without subjecting the patient to additional distress.

\section{References}

1. Cameron SM, Whitlock WL, Tabor MS (1996) Foreign body aspiration in dentistry: a review. J Am Dent Assoc 127: 1224-1229. [Crossref]

2. Silva RF, Martins EC, Prado FB, Jacy RC Jr, Eduardo D Jr (2009) Endoscopic removal of an endodontic file accidentally swallowed: clinical and legal approaches. (Journal Compilation) Aust Endod J pp. 1-3.

3. Bergermann M, Donald PJ, Wengen DF (1992) Screwdriver aspiration. A complication of dental implant placement. Int J Oral Maxillofac Surg 21: 339-341. [Crossref]

4. Gibbs JS, Murdoch LJ, Goldstraw P, Buller NP (1994) Removal of a dental post from the bronchus by interventional cardiovascular techniques. Thorax 49: 5260-527. [Crossref]

5. Mejia JL, Donado JE, Posada A (1996) Accidental swallowing of a dental clamp. $J$ Endod 22: 619-620. [Crossref]
6. Fishelberg G, Hook D (2003) Patient safety during endodontic therapy using current technology: a case report. J Endod 29: 683-684. [Crossref]

7. Ulku R, Baskan Z, Yavuz I (2005) Open surgical approach for a tooth aspirated during dental extraction: a case report. Aust Dent J 50: 49-50. [Crossref]

8. Kim IH, Kim HC, Koh KH, Kim SH, Kim SW, et al. (2007) Journey of a swallowed toothbrush to the colon. Korean J Intern Med 22: 106-108. [Crossref]

9. Kuo SC, Chen YL (2008) Accidental swallowing of an endodontic file. Int Endod J 41: 617-622. [Crossref]

10. Grossman L (1971) Prevention in endodontic practice. J Am Dent Assoc 8: 395-396. [Crossref]

11. Webb WA (1988) Management of foreign bodies of the upper gastrointestinal tract Gastroenterology 94: 204-216. [Crossref]

12. Oncel M (2012) Accidental swallowing of the head of a dental mirror: report of a rare case. Journal of dental sciences 7: 199-202.

13. Prakash UBS, Cortese DA (1994) Tracheobronchial foreign bodies. in: U.B.S. Prakash (Ed) Bronchoscopy. (2nd Edn) Raven, New York pp. 253-277.

14. Worthington P (1996) Ingested foreign body associated with oral implant treatment: report of a case. Int J Oral Maxillofac Implants 11: 679-681. [Crossref]

15. Haug RH, Kimberly D, Brandt CP (1993) Management of an ingested iatrogenic foreign body: report of a case. J Oral Maxillofac Surg 51: 593-596. [Crossref]

16. Eisen GM, Baron TH, Dominitz JA, Faigel DO, Goldstein JL, et al. (2002) Guideline for the management of ingested foreign bodies. Gastrointest Endosc 55: 802-806. [Crossref]

17. ElBadrawy HE (1985) Aspiration of foreign bodies during dental procedures. $J$ Can Dent Assoc 51: 145-147. [Crossref]

18. Israel HA, Leban SG (1984) Aspiration of an endodontic instrument. J Endod 10: 452 454. [Crossref]

19. Ong TK, Lancer JM, Brook IM (1988) Inhalation of a denture fragment complicating facial trauma. Br J Oral Maxillofac Surg 26: 511-513. [Crossref]

20. Knowles JE (1991) Inhalation of dental plates--a hazard of radiolucent materials. $J$ Laryngol Otol 105: 681-682. [Crossref]

21. MF Lyons II, AM Tsuchida (1993) Foreign bodies of the gastrointestinal tract. Med Clin North Am 77: 1101-1114.

22. Saraf HP (2012) Accidental ingestion of endodontic file: a case report. Hindawi publishing corporation. case reports in dentistry.

Copyright: (C2019 Selvendran K E. This is an open-access article distributed under the terms of the Creative Commons Attribution License, which permits unrestricted use, distribution, and reproduction in any medium, provided the original author and source are credited. 